\title{
Adenoma of the Nonpigmented Ciliary Body and Iris Epithelium in Mexican Mestizo Patients
}

\author{
Juan Carlos Serna-Ojeda ${ }^{a}$ Enrique Ariza-Camacho ${ }^{a}$ \\ Alberto Collado-Solórzano ${ }^{a} \quad$ Blanca C. Flores-Sánchez ${ }^{b}$ \\ Abelardo A. Rodríguez-Reyes ${ }^{b} \quad$ Emiliano Fulda-Graue ${ }^{a}$ \\ anstituto de Oftalmologia 'Conde de Valenciana', and b Asociacion Para Evitar la Ceguera en \\ Mexico (APEC), Mexico City, Mexico
}

\section{Key Words}

Adenoma of the nonpigmented ciliary epithelium · Sclerouvectomy · Immunohistochemistry

\section{Abstract}

The adenoma of the nonpigmented ciliary epithelium is a benign rare tumor, which may present with different clinical characteristics and requires resection along with histopathologic analysis and the identification of specific immunohistochemical markers for an accurate diagnosis. Here, we report a case series of 4 patients in a Mexican mestizo population with this diagnosis, their clinical features, the ultrasound imaging characteristics and the histopathological and immunohistochemical findings.

(C) 2015 S. Karger AG, Base

\section{Introduction}

The first description of the adenoma of the nonpigmented ciliary epithelium (NPCE) was done by Shields et al. in 1983 [1]. The adenoma of the NPCE is a benign rare tumor usually described in the literature in case reports or small case series. Because of its origin, the clinical presentation is varied without an established pattern and it may be confused 
Serna-Ojeda et al.: Adenoma of the Nonpigmented Ciliary Body and Iris Epithelium in Mexican Mestizo Patients

Table 1. Clinical characteristics of adenoma of the NPCE and iris epithelium

\begin{tabular}{|c|c|c|c|c|c|c|c|}
\hline $\begin{array}{l}\text { Case } \\
\text { No. }\end{array}$ & $\begin{array}{l}\text { Age, } \\
\text { years }\end{array}$ & $\begin{array}{l}\text { Gen- } \\
\text { der }\end{array}$ & Eye & $\begin{array}{l}\text { Presenting } \\
\text { symptom }\end{array}$ & $\begin{array}{l}\text { Approximate } \\
\text { time to symptom } \\
\text { onset }\end{array}$ & Clinical appearance & Other findings \\
\hline 1 & 47 & M & OD & $\begin{array}{l}\text { Blurry vision } \\
\text { and low visual } \\
\text { acuity }\end{array}$ & 3 months & $\begin{array}{l}\text { Nodular hypopigmented lesion } \\
\text { in extreme peripheral retina of } \\
\text { apparent subretinal origin }\end{array}$ & $\begin{array}{l}\text { Inferior exudative } \\
\text { retinal detachment }\end{array}$ \\
\hline 2 & 15 & $\mathrm{~F}$ & OD & $\begin{array}{l}\text { Iris color } \\
\text { change }\end{array}$ & 1 year & $\begin{array}{l}\text { Pink, round, slightly elevated and } \\
\text { barely vascularized lesion, arising } \\
\text { from the inferior peripheral iris } \\
\text { stroma }\end{array}$ & $\begin{array}{l}\text { Notable growth of the } \\
\text { lesion, producing slight } \\
\text { dyscoria after } 11 \text { months } \\
\text { of clinical observation }\end{array}$ \\
\hline 3 & 75 & M & OS & $\begin{array}{l}\text { Decreasing } \\
\text { visual acuity }\end{array}$ & 6 months & $\begin{array}{l}\text { Hypopigmented, nodulated lesion } \\
\text { behind the iris, more evident on } \\
\text { gonioscopy, located superiorly }\end{array}$ & $\begin{array}{l}\text { Tumor in contact with } \\
\text { the lens, causing cataract } \\
\text { formation and mild } \\
\text { subluxation }\end{array}$ \\
\hline 4 & 53 & M & OD & $\begin{array}{l}\text { Iris color } \\
\text { change }\end{array}$ & 6 months & $\begin{array}{l}\text { Inferotemporal hypopigmented } \\
\text { lesion in the pupillary margin of } \\
\text { the iris }\end{array}$ & $\begin{array}{l}\text { Adjacent sentinel vessel } \\
\text { visible in the sclera }\end{array}$ \\
\hline
\end{tabular}

$\mathrm{M}=$ Male; $\mathrm{F}$ = female; $\mathrm{OD}$ = right eye; OS = left eye.

with other tumors. In order to make the diagnosis of this adenoma, resection is needed along with histopathological analysis and the identification of specific immunohistochemical markers.

We present 4 patients in the Mexican mestizo population diagnosed with adenoma of the NPCE who presented with different clinical characteristics and underwent excisional biopsy. We report the clinical features, the ultrasound imaging characteristics, as well as the histopathological and immunohistochemical findings.

\section{Case Series}

A summary of the clinical findings is shown in table 1 . Out of the 4 patients, 3 were male, with a median age at presentation of 50 years (range 15-75). The right eye was affected in 3 cases. Half of the patients presented with decreased visual acuity and the other half with changes in iris pigmentation. In most cases, the ophthalmic examination of the tumor revealed a nodular hypopigmented lesion. The clinical images of all cases are shown in figure 1.

The ultrasound findings included the presence of a solid mass of homogeneous density on B-mode scanning and high internal reflectivity seen in standardized A-mode echography. The 20-MHz frequency immersion probe identified a lesion originating in the ciliary body in some patients. In other patients, ultrasound biomicroscopy showed the anatomical origin of the lesion. Some of the ultrasound images are shown in figure 2 .

After informed consent was obtained from all patients, an excisional biopsy with partial lamellar sclerouvectomy was performed. Case 1 required a 23-gauge vitrectomy at the same surgical time to introduce heavy liquids for retinal reattachment and silicone oil for adequate tamponade.

Histopathological examination revealed a benign neoplasm composed of sheets of cells with clear cytoplasm surrounded by a well-defined basement membrane showing occasional tubular differentiation, intermingled with some chronic inflammatory cells. Neither cellular atypia nor mitotic figures were found. The immunohistochemical analysis revealed diffuse and strong positivity for vimentin, S-100, epithelial 
Ocular Oncology

and Pathology

Serna-Ojeda et al.: Adenoma of the Nonpigmented Ciliary Body and Iris Epithelium in Mexican Mestizo Patients
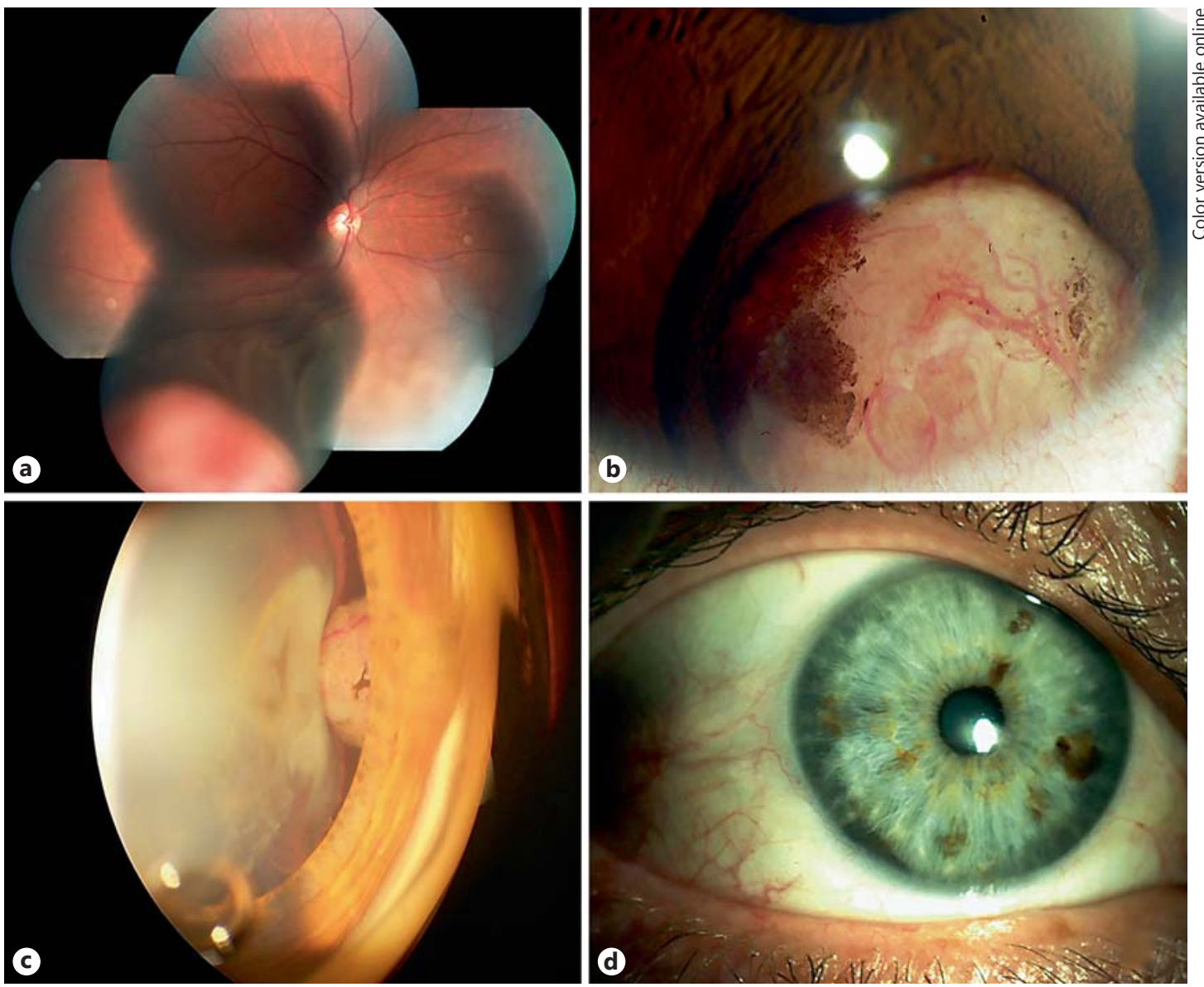

Fig. 1. a Case 1: inferior exudative retinal detachment with an associated nodular hypopigmented lesion in the extreme retinal periphery. $\mathbf{b}$ Case 2: round, slightly elevated and barely vascularized lesion, arising from the inferior peripheral iris stroma 11 months after initial presentation. c Case 3: hypopigmented, nodular lesion behind the iris touching the lens. $\mathbf{d}$ Case 4 : inferotemporal, hypopigmented lesion arising from the margin of the iris.

membrane antigen (EMA) and neuron-specific enolase (NSE), as well as negative melanoma and smooth muscle markers (HMB-45, melan-A and smooth muscle actin). These findings were consistent with the diagnosis of adenoma of the NPCE. The immunohistochemistry stains are illustrated in figure 3.

\section{Discussion}

Primary tumors of the NPCE may be congenital, like the medulloepithelioma, or acquired like the adenoma or adenocarcinoma [2]. The adenoma of the NPCE, appearing as a defined and multilobulated mass in adults, usually presents with visual loss [3], but some of the patients may present with subjective changes in the iris pigmentation. It can develop during virtually any decade of life, as observed in this case series.

Due to the location of the growing tumor, the adenoma of the NPCE can present with a wide variety of clinical manifestations and, despite its benign nature, it can cause severe local complications. If accompanied by a retinal detachment, as seen in case 1 , the vision can be 
Ocular Oncology

and Pathology
Ocul Oncol Pathol 2015;1:248-253

DOI: 10.1159/000381066

Serna-Ojeda et al.: Adenoma of the Nonpigmented Ciliary Body and Iris Epithelium in Mexican Mestizo Patients
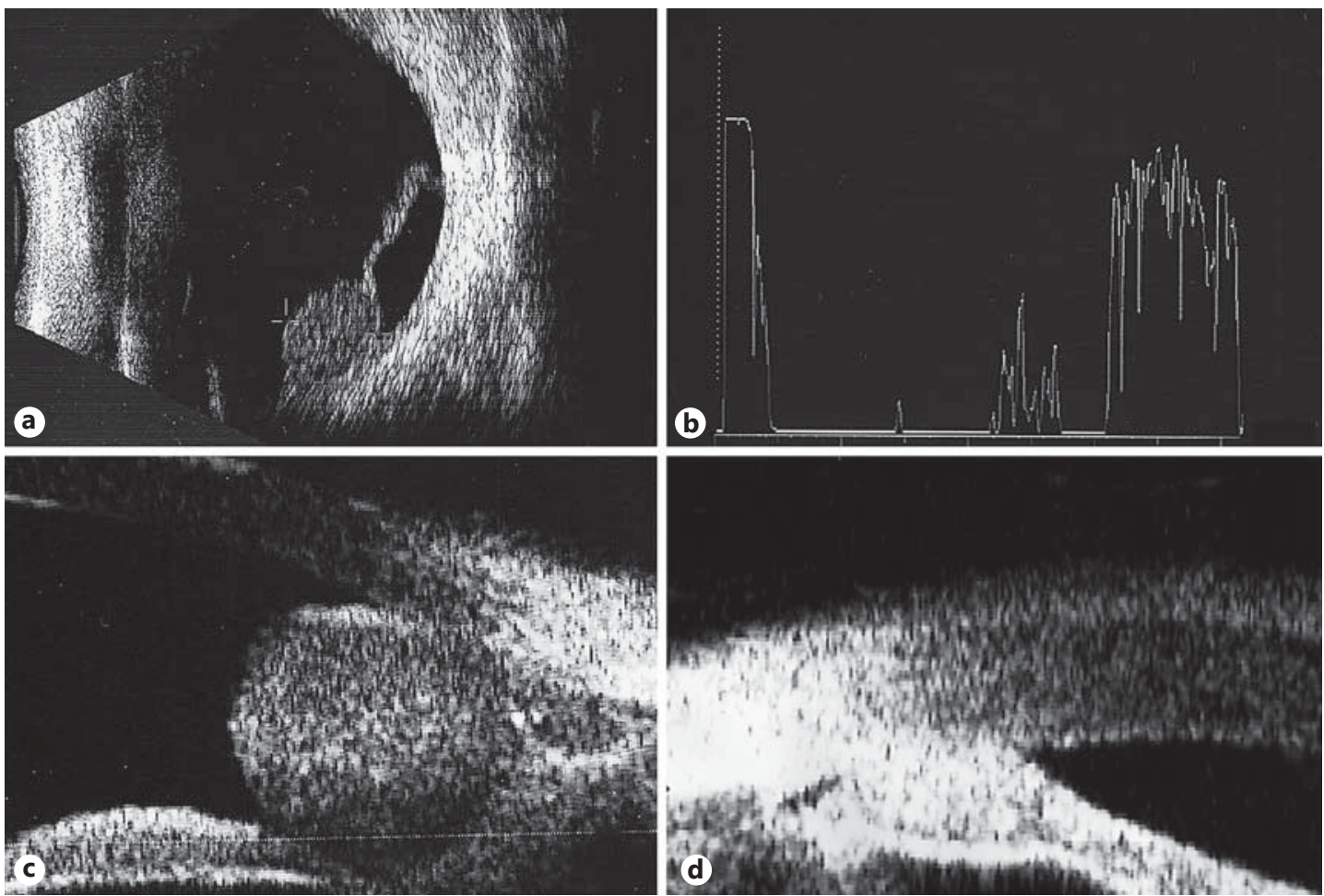

Fig. 2. a Case 1: B-mode ultrasound showing a solid mass of homogeneous density, measuring $7 \times 6 \mathrm{~mm}$, associated with retinal detachment. b Case 1: standardized A-mode echography demonstrating high internal reflectivity. c Case 2: ultrasound biomicroscopy at presentation showing a homogeneous lesion of $2 \times 3 \mathrm{~mm}$ with corneal endothelial touch but without lens contact. $\mathbf{d}$ Case 4: ultrasound biomicroscopy showing the mass displacing the iris forward.

severely compromised. Case 3 presented with lens subluxation and cataract formation as a result of tumor growth. The adenoma of the NPCE has previously been reported as a rare cause of cataract in young patients [4]. Other clinical manifestations include rubeosis iridis [5], neovascularization of the optic disc and cystoid macular edema [6], as well as anterior uveitis and glaucoma [7].

On ultrasound imaging, it appears as a demarcated lesion with homogeneous density and high-to-medium reflectivity. Ultrabiomicroscopy is useful for the diagnosis of ciliary body tumors and for their surgical approach.

The differential diagnosis may include a variety of neoplasms arising from the ciliary body and iris, including amelanotic melanomas, which are difficult to differentiate from adenomas because they can have nonclassical features [8]. A high degree of clinical suspicion is required when evaluating these tumors. Local resection with partial lamellar sclerouvectomy is an effective therapeutic approach that allows an accurate diagnosis without the need of an enucleation [9]. Although this technique is considered as a safe method for the treatment of lesions of the ciliary body [10], complications may present such as choroidal hemorrhage, retinal detachment or cataract formation.

The accurate diagnosis is made by histopathologic findings and confirmed by immunohistochemistry with positive markers for vimentin, S-100, EMA and NSE, and negative markers for HMB-45, melan-A and smooth muscle actin to rule out malignant melanoma and leiomyoma, respectively. 


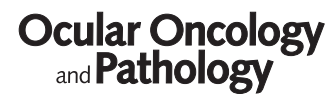

Ocular Oncology
and Pathology
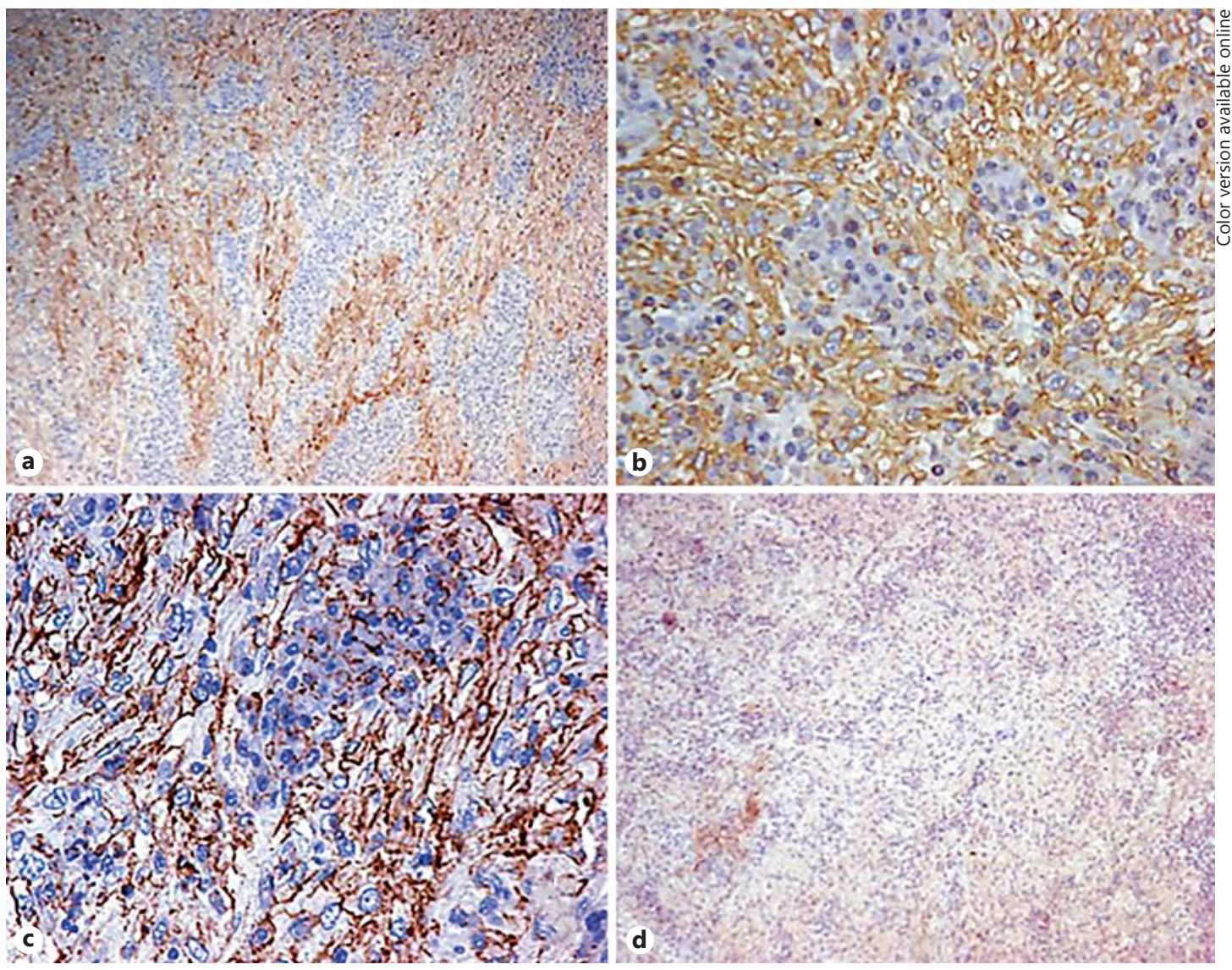

Fig. 3. Case 1: photomicrograph of the tumor showing diffuse and strong cytoplasmic positivity for S-100 (a), vimentin (b), EMA (c), and NSE (d).

This study adds to the body of literature of adenoma of the NPCE, presenting cases occurring in a specific population with different clinical characteristics. In conclusion, the adenoma of the NPCE is a rare tumor, which is oftentimes misdiagnosed as another type of neoplasm. To confirm the diagnosis, histopathological analysis and immunohistochemistry of the tissue obtained from the incisional or excisional biopsy are mandatory.

\section{Disclosure Statement}

The authors have no financial interests relating to the materials presented in this paper.

\section{References}

1 Shields JA, Augsburger JJ, Wallar PH, Shah HG: Adenoma of the nonpigmented epithelium of the ciliary body. Ophthalmology 1983;90:1528-1530.

2 Shields JA, Eagle RC Jr, Shields CL, De Potter P: Acquired neoplasms of the nonpigmented ciliary epithelium (adenoma and adenocarcinoma). Ophthalmology 1996;103:2007-2016.

3 Mansoor S, Qureshi A: Ciliary body adenoma of non-pigmented epithelium. J Clin Pathol 2004;57:997-998.

4 Appolloni R, Modesti M, Pecorella I, Palladino D, Ciocci L: Uncommon cause of juvenile cataract: adenoma of the nonpigmented ciliary epithelium. J Cataract Refract Surg 2008;34:1997-2001. 
5 Papastefanou VP, Cohen VM: Ciliary-body adenoma of the non-pigmented epithelium with rubeosis iridis treated with plaque brachytherapy and bevacizumab. Eye (Lond) 2012;26:1388-1390.

6 Suzuki J, Goto H, Usui M: Adenoma arising from nonpigmented ciliary epithelium concomitant with neovascularization of the optic disk and cystoid macular edema. Am J Ophthalmol 2005;139:188-190.

7 Biswas J, Neelakantan A, Rao BS: Adenoma of nonpigmented epithelium of the ciliary body presenting as anterior uveitis and glaucoma: a case report. Indian J Ophthalmol 1995;43:137-140.

8 Cursiefen C, Schlötzer-Schrehardt U, Holbach LM, Naumann GO: Adenoma of the nonpigmented ciliary epithelium mimicking a malignant melanoma of the iris. Arch Ophthalmol 1999;117:113-116.

9 Chen ZQ, Fang XY: Adenoma of nonpigmented epithelium in ciliary body: literature review and case report. J Zhejiang Univ Sci B 2007;8:612-615.

10 Wei WB, Yang WL, Hu SM, Li B: Local excision of ciliary body tumors: a long-term prospective cohort study in China. Chin Med J (Engl) 2008 5;121:2152-2156. 